\title{
Gemlik Tipi Zeytinlerin Olgunlaşma Dönemindeki Fenolik, Flavonoid ve Antioksidan Kapasitesindeki Değişiklikler
}

\author{
Merve KÖSE${ }^{1}$, Duygu SEMİZOĞLU ${ }^{1}$, Cemal KASNAK*11, Recep PALAMUTOĞLU ${ }^{1}$ \\ ${ }^{1}$ Afyon Kocatepe Üniversitesi, Afyon Sağlık Yüksekokulu, Beslenme ve Diyetetik Bölümü, Afyonkarahisar, Türkiye
}

Geliş Tarihi: 09.05.2018

"Sorumlu Yazar: ckasnak@gmail.com

Kabul Tarihi: 25.07 .2018

\section{$\ddot{O} z$}

Bu çalıșmada, Muğla Fethiye ilçesinde farklı olgunlașma dönemlerinde toplanan Gemlik tipi zeytinlerin fenolik bileşenleri ve antioksidan kapasiteleri incelenmiştir. Zeytin 2 haftalık periyotlarda 4 kez toplandı. Toplanan zeytinlerde DPPH, ABTS, fenolik bileşik ve flavonoid içerik değişiklikleri tespit edildi. En yüksek fenolik bileşik, flavonoid ve ABTS miktarı, 3. periyotta toplanan zeytinlerde tespit edildi (sırasıyla; $657.02 \mathrm{mg} / 100 \mathrm{~g}$ kateşin eşdeğeri, $397.03 \mathrm{mg}$ / $100 \mathrm{~g}$ kateşin eşdeğeri, $527.44 \mathrm{mg} / 100 \mathrm{~g}$ Trolox eşdeğeri). Birinci periyotta toplanan zeytinlerde DPPH'nin en yüksek miktarı 20,41 mg / $100 \mathrm{~g}$ Trolox eşdeğeri olarak bulundu.

Anahtar Kelimeler: Antioksidan, Fenolik bileşik, Flavonoid, Zeytin, ABTS, DPPH.

\section{Changes in Amount of Phenolic, Flavonoid and Antioxidant in Ripening Period of Gemlik Type Olive}

\begin{abstract}
Phenolic compounds in the olive are very important because they affect the oxidative stability and sensory properties of the table olive. In this study, phenolic component and antioxidant capacities of Gemlik type olives collected from Fethiye district of Muğla in different ripening periods were investigated. Olive was collected during 4 times in 2-week periods. DPPH, ABTS, phenolic compound and flavonoid content changes were detected in the collected olives. The highest phenolic compound, flavonoid and ABTS amount were detected in olives collected during the 3rd period. (Respectively: $657.02 \mathrm{mg} / 100 \mathrm{~g}$ catechin equivalent, $397.03 \mathrm{mg} / 100 \mathrm{~g}$ catechin equivalent, $527.44 \mathrm{mg} / 100 \mathrm{~g}$ Trolox equivalent). The highest amount of DPPH was found as $20,41 \mathrm{mg} / 100 \mathrm{~g}$ Trolox equivalent in olives collected in the 1st period.
\end{abstract}

Keywords: Antioxidant, Phenolic compound, Flavonoid, Olive, ABTS, DPPH. 


\section{Giriş}

Zeytin yetiştiriciliği ülkemizde Ege, Akdeniz, Marmara ve Güney Doğu Anadolu bölgelerinde yapılmaktadır. Zeytin Olea europa olarak bilinen bir ağacın meyvesidir. Zeytinin bileşimi \%40 su, \%20-35 yağdan oluşmaktadır. Zeytin meyvesinin \%1-2'lik kısmı meyve kabuğu, \%63-86'lık kısmı meyve eti \%10-30'luk kısmı ise meyve çekirdeğinden oluşmaktadır. Zeytinde bulunan yağın büyük bir bölümü meyve eti olarak bilinen kısımda bulunmaktadır (Yemişçioğlu ve ark. 2001). Zeytinin kimyasal ve fiziksel özellikleri türü, yetiştiği toprak ve coğrafi alanına bağlıdır. Zeytinin yaşı, karakteristik türü, yetiştirildiği yer, genel coğrafik alan ve toprakta bulunan organik ve inorganik bileşikler zeytin ve zeytinyağının kalitesinde etkindirler. Ayrıca zeytinin olgunlaşma dereceleri de zeytinin kimyasal bileşiminde bir etkiye sahiptir (Demir 2013).

Zeytin meyvesinin olgunlaşma süresi aylarca devam edebilir ve zeytinin gelişim yetişme bölgesine, zeytinin çeşidine, sıcaklığa ve tarım uygulamalarına göre farklılık gösterir. Olgunlaşmanın ilk aşamasından yeşil olgunluktaki meyvelerin boyutunun son haline ulaşmasına kadar olan sürece yeşil olum zamanı denir. $\mathrm{Bu}$ süreçten sonra meyvenin olgunlaşması boyunca zeytinin yüzeyinde bulunan klorofil pigmentlerinin yerini antosiyaninler alır. Bu da zeytinin yüzey rengine göre 'benekli', 'mor' ve 'siyah' olum zamanları olarak tanımlanmasını sağlar.

Zeytin polifenollerin önemli bir kaynağını oluşturmaktadır. Sağlığımız için oldukça önemli ve organizmayı koruyucu etkili olan antioksidanların bir dizisini içermektedir (Tokuşoğlu,2008). Fenolik bileşikler, yüksek antioksidan etkileri ile birlikte, zeytine önemli yapısal ve duyusal özellikler katmaktadır (Kadakal, 2009).

Bu çalışmada, Muğla'nın Fethiye ilçesinden farklı olgunlaşma dönemlerinde toplanan Gemlik tipi zeytinlerin fenolik bileşenleri ve antioksidan kapasiteleri incelenmiştir.

\section{Materyal ve Metot}

\subsection{Materyal}

Muğla'nın Fethiye ilçesinden Ekim-Kasım 2017 tarihlerinde ikişer haftalık periyotlar halinde 4 defa toplanan Gemlik tipi zeytinlerde analizler gerçekleştirildi. Örnekler Uceda ve Frías'ın (1975) çalşımasında bulunan olgunluk indeksine ekleme yapılarak hazırladığımız indekse göre (Modifiye olgunluk indeksi: kabuk renginin öznel değerlendirilmesi, 0-2 yeşil, 2-3 alacalı, 3-5 tavşanyüreği ve 5-7 siyah) 4 aşamada toplandı. Her olgunlaşma aşamanın arasında geçen süre 2 haftadır. 


\subsection{Metot}

Metanolik ekstrakt

Zeytinler toplandıktan sonra Karadeniz ve ark., (2005)'nın yöntemiyle metanolik ekstereleri çıkarılarak $-18^{\circ} \mathrm{C}$ 'de analizler yapılana kadar depolanmıştır.

Toplam Fenolik Madde Tayini

Zeytinlerden elde edilen metanolik ekstrakt, folin ciocalteu reaktifi ve su sirasiyla 1, 1, 14 oranında karıştırılıp 3 dakika bekledikten sonra $2 \mathrm{ml} \%$ 20'li $\mathrm{Na}_{2} \mathrm{CO}_{3}$ eklendi ve yeniden karıştırıldı. Karışım $25{ }^{\circ} \mathrm{C}$ 'de 1 saat su banyosunda bekletildikten sonra $720 \mathrm{~nm}$ 'de spektrofotometrede çözücüye karşı okundu. Sonuçlar kateşin cinsinden belirlendi (Karadeniz ve ark., 2005).

Toplam Flavanoid Tayini

Flavanoid madde miktarı Karadeniz ve ark., (2005) kullandığı yöntemle belirlenmiştir. Hazırlanan karışım 510 nm'de spektrofotometrede okundu. Sonuçlar kateşin cinsinden belirlendi.

DPPH (2,2-diphenyl-1-picrylhydrazyl) Analizi

Brand-Williams ve ark., (1995) yönteminde bazı değişiklikler yapılarak belirlendi. $4 \mathrm{M}$ hazırlanan DPPH çözeltisinden $0.4 \mathrm{ml}$ alınıp üzerine $1.6 \mathrm{ml}$ örnek eklenerek 30 dakika karanlıkta bekletildi. $517 \mathrm{~nm}$ dalga boyunda kör alkol DPPH karışımına karşı okundu ve trolox eğrisine karşılık konsantrasyonu bulundu.

DPPH süpürme etkisi \% $\equiv\left(1-((\text { Aörnek/Ablank }))^{*} 100\right.$

ABTS 2,2'-Azino-bis (3-ethylbenzthiazoline-6-sulfonic acid) Analizi

Re ve ark. (1999) yönteminde bazı değişiklikler yapılarak belirlendi. $10 \mathrm{ml} 0.63 \mathrm{Mm}$ potasyum persülfat, $10 \mathrm{ml} 1.8 \mathrm{mM}$ ABTS çözeltisi karıştırılarak karanlıkta 16-24 saat bekletildi. Solüsyonun $732 \mathrm{~nm}$ 'de spektrofotometredeki absorbas1 (0.700 \pm 0.030$)$ olana kadar metanol ilave edildi. $20 \mu \mathrm{l}$ örnek $1.980 \mathrm{ml}$ solüsyon ile karıştırılarak köre karşı 732 nm'de okundu ve trolox eğrisine karşılık konsantrasyonu bulundu.

\section{Bulgular ve Tartışma}

Gemlik zeytinlerinin ağaçta olgunlaşma periyotlarına göre toplam fenolik madde miktarları, flavonoid miktarları ve antioksidan kapasiteleri çizelge 1'de gösterilmiştir.

Çizelge 1'de görüldüğü gibi ABTS değerleri en düşük yeşil zeytinde görülürken, en yüksek değer 3. olgunlaşma döneminde gözlemlendi. DPPH değerlerinde en yüksek miktar yeşil zeytinde görülürken olgunlaşma periyodu ilerledikçe düşüş gözlemlendi, en düşük değer siyah zeytinde görüldü. Toplam Fenolik madde miktarı ve flavonoid miktarı en düşük yeşil zeytinde bulundu. Her iki sonuç ta 3. olgunlaşma periyoduna kadar yükseliş gösterdi ve 4. olgunlaşma periyodunda düşüş 
görüldü. $\mathrm{Bu}$ düşüşün nedeninin büyük moleküllü fenolik bileşiklerin hidrolizasyonu sonucu olduğunu düşünülmektedir. Büyük molekülllü fenolik bileşikler olgunlaşmanın sonlarına doğru parçalanarak tirozol, hidroksitirozol ve elenolik asit glikozitleri gibi bileşikler ortaya çıkar (Amiot ve ark., 1989).

Çizelge 1. Zeytinlerin olgunlaşma periyotlarına göre abts, dpph, toplam fenolik madde ve flavonoid değişimi

\begin{tabular}{lllccccc}
\hline Gemlik Zeytin & & & & & & & \\
Olgunlaşma Periyodu & & $\mathrm{N}$ & Minimum & Maksimum & Ortalama & Std. Sapma & Varyans \\
\hline Zeytin1 (Yeşil Zeyin) & ABTS & 2 & 403.10 & 502.77 & 452.93 & 70.47 & 4966.56 \\
& DPPH & 2 & 20.35 & 20.46 & 20.41 & 0.08 & 0.01 \\
& TFM & 2 & 312.98 & 313.77 & 313.37 & 0.56 & 0.32 \\
& Flavonoid & 2 & 130.63 & 143.13 & 136.88 & 8.83 & 78.13 \\
\hline Zeytin2 ( Alacal1) & ABTS & 2 & 524.05 & 524.20 & 524.12 & 0.11 & 0.01 \\
& DPPH & 2 & 19.97 & 20.01 & 19.99 & 0.03 & 0.001 \\
& TFM & 2 & 525.28 & 526.87 & 526.07 & 1.12 & 1.26 \\
& Flavonoid & 2 & 265.00 & 286.09 & 275.55 & 14.92 & 222.48 \\
\hline Zeytin3 (Tavşanyüreği) & ABTS & 2 & 526.80 & 528.08 & 527.44 & 0.90 & 0.81 \\
& DPPH & 2 & 19.28 & 19.63 & 19.46 & 0.24 & 0.06 \\
& TFM & 2 & 655.83 & 658.21 & 657.02 & 1.68 & 2.83 \\
& Flavonoid & 2 & 390.00 & 404.06 & 397.03 & 9.94 & 98.88 \\
\hline Zeytin4 (Siyah) & ABTS & 2 & 526.34 & 526.95 & 526.65 & 0.43 & 0.19 \\
& DPPH & 2 & 15.02 & 16.04 & 15.53 & 0.73 & 0.53 \\
& TFM & 2 & 499.09 & 526.87 & 512.98 & 19.64 & 385.80 \\
& Flavonoid & 2 & 308.75 & 318.13 & 313.44 & 6.63 & 43.94 \\
\hline
\end{tabular}

TFM: Toplam Fenolik Madde

Aynı zamanda olgunlaşmayla birlikte antosiyanin miktarı artarak yeşil zeytine rengini veren klorofile baskınlık sağlar ve zeytinde pembe-mor renk oluşumuna neden olur. Fenolik bileşiklerin parçalanması antioksidan kapasiteyi azaltırken antosiyanin oluşumu bunu kısmen dengeler. Keçeli ve Büyükaslan (2008)'da bize sonuçlara benze olarak Gemlik tipi zeytinlerin olgunlaşmayla beraber toplam fenolik madde içeriklerinin \% 25,9 azaldığını tespit etmişlerdir. Çalışmamızda da 3. aşamadaki Gemlik zeyinlerinin toplam fenolik madde içeriği 4. aşamada \% 28 oranında düşüş gösterdi.

Yeşil zeytindeki ABTS miktarının standart sapması ve varyansı diğer olgunlaşma periyotlardaki zeytinlere göre yüksektir. İlerleyen olgunlaşma periyotlarında ABTS miktarlarının standart sapma değerleri 1 altına düşmüştür. Bu durum yapılan analizlerin güvenilirliğindeki artışın göstergesidir. Varyans değerleri de, yeşil zeytin hariç, örnekler arasındaki ABTS miktarlarının dağılımının dengeli olduğunu göstermektedir. DPPH miktarlarındaki standart sapma ve varyans 
değerleri tüm olgunlaşma periyotlarında dengeli bulundu. Toplam fenolik madde miktarlarının standart sapma ve varyans değerleri ilk üç olgunlaşma periyodunda dengeli iken 4. olgunlaşma periyodunda 19.64'e çıktı. Bu durum her örnek için yapılan iki tekrarın arasındaki farkın bir miktar arttığını gösterir. Flavonoid miktarlarındaki standart sapma ve varyans değerlerinde önce bir artış ve daha sonra düşüş görüldü.

Çizelge 2.'de Gemlik zeytinlerinin olgunlaşma periyotlarındaki antioksidan aktivite, toplam Fenolik ve flavonoid içeriklerinin değişimleri görülmektedir.

Çizelge 2. Gemlik zeytinlerinin olgunlaşma periyotlarındaki antioksidan aktivite, toplam Fenolik ve flavonoid içeriklerinin değişimleri

\begin{tabular}{lcccc}
\hline & $\begin{array}{c}\text { Zeytin1 } \\
\text { (Yeşil Zeyin) }\end{array}$ & $\begin{array}{c}\text { Zeytin2 } \\
\text { (Alacalı) }\end{array}$ & $\begin{array}{c}\text { Zeytin3 } \\
\text { (Tavşan Yüreği) }\end{array}$ & $\begin{array}{c}\text { Zeytin4 } \\
\text { (Siyah) }\end{array}$ \\
\hline DPPH & $20.41 \mathrm{a}$ & $19.99 \mathrm{a}$ & $19.46 \mathrm{a}$ & $15.53 \mathrm{~b}$ \\
ABTS & $452.93 \mathrm{a}$ & $524.12 \mathrm{a}$ & $527.44 \mathrm{a}$ & $526.65 \mathrm{a}$ \\
TFM & $313.37 \mathrm{a}$ & $526.07 \mathrm{~b}$ & $657.02 \mathrm{c}$ & $512.98 \mathrm{~b}$ \\
Flavonoid & $136.88 \mathrm{a}$ & $275.55 \mathrm{~b}$ & $397.03 \mathrm{~d}$ & $313.44 \mathrm{c}$ \\
\hline
\end{tabular}

Çizelge 2'de görüldüğü gibi DPPH düzeylerinde ilk üç olgunlaşma döneminde belirgin bir değişiklik olmazken 4. olgunlaşma periyodunda düşüş yönünde değişiklik izlendi. Tüm olgunlaşma periyotlarında ABTS düzeyinde belirgin bir değişiklik görülmedi. Zeyinin olgunlaşma periyodunda toplam fenolik madde ve flavonoid miktarlarında 2. olgunlaşma döneminde değişiklikler görülürken, 3. olgunlaşma döneminde ise 1. olgunlaşma periyoduna göre belirgin değişiklikler izlendi.

Fernandez-Orozco vd. (2011)'nin yaptığ madde miktarları 25675.3 ila 108833.9 mg tyrosol eşdeğeri / kg kuru ağırlık, geleneksel üretim zeytinlerde 30269.7 ila $93707.77 \mathrm{mg}$ tyrosol eşdeğeri/kg kru ağırlık olarak verilmiştir. Aynı çalışmada DPPH EC50 değerleri (DPPH'nin\% 50 azaltılması için substrat konsantrasyonu), organik ve geleneksel zeytin çeşitleri için sırasıyla 265.1 - 1007.3 ve 309.6 - 993.8 g kuru meyve / g DPPH arasindadir.

Pirgün ve Keçeli (2008)'nin yaptığı çalışmada Gemlik ve Halhalı zeytinlerinin toplam fenol içeriğinin olgunluk aşaması ve çeşide bağlı olarak önemli ölçüde değiştiği bulunmuştur. Keçeli ve Büyükaslan (2008)'ın yaptığı çalışmada toplam fenol içeriği bakımından en iyi olan ilk derim Halhalı çeşidinin antioksidan etkinlik bakımından BHT ve Gemlik çeşidine göre daha etkili olduğunu bildirmektedir. Ayrıca halhalı çeşidinin olgunluk sonunda antioksidan aktivitesinin önemli derecede düştüğünü ve toplam fenol içeriği ile antioksidan aktivite arasında sıkı bir ilişki 
olduğunu bildirmektedir. Kaya ve Mutlu (2010) Gemlik zeytinlerinden olgunlaşma süresince elde edilen fenolik ekstraktların antioksidan etkisinin BHT ve BHA'dan daha iyi ve/veya etkilerinin karş1laştırılabilir düzeyde olduğu bildirmiştir $(\mathrm{p}<0.01)$.

\section{Sonuçlar ve Önerliler}

Olgunlaşmanın 3. evresinde hasat edilen zeytinlerin fenolik ve flavonoid madde miktarları diğer olgunlaşma evrelerine göre daha yüksek çıkmıştır. Gemlik tipi zeytinlerin 3. olgunlaşma evresine kadar olan süreçte fenolik ve flavonoid madde miktarları artarak ilerlemiş, zeytinin tam olgunlaşmasıyla beraber 4. olgunlaşma döneminde azalma meydana gelmiştir. Ancak azalma meydana gelmiş olsa da 1. ve 2. olgunlaşma evresindeki zeytinlere göre oran daha fazladır. DPPH değerleri ise zeytinin olgunlaşmaya başlamasıyla giderek azalmıştır. En az antioksidan değeri 4. olgunlaşma evresindeki zeytinde saptanmıştır. ABTS değeri en düşük olan zeytin yeşil zeytindir. 2. Olgunlaşma döneminde yeşil zeytine göre artış görülmüş, 3. ve 4. Olgunlaşma döneminde belirgin değişiklik olmamıştır. Gemlik tipi zeytinlerin olgunlaşma periyodunda fenolik ve flavonoid madde miktarında artış gösterdiği, ancak olgunlaşarak tamamen siyah-mor renk almasıyla birlikte toplam fenolik madde ve flavonoid miktarlarının düştüğü görüldü. Antioksidan kapasite bakımından zeytinin olgunlaşmasıyla beraber DPPH miktarında azalma $(\mathrm{p}<0.05)$, ABTS miktarında artış ( $p>0.05)$ görüldü. Sonuç olarak tamamen siyah-mor renk alarak olgunlaşan zeytinlerin toplam fenolik ve flavonoid madde miktarlarının düştüğü, buna bağlı olarakta antioksidan kapasitesinin azaldı̆̆ 1 belirlendi.

\section{Kaynaklar}

Amiot, M.J., Fleuriet, A., Macheix, J.J., (1986). Importance and Evolution of Phenolic Compounds in Olive During Growth and Maturation. J. Agric. Food Chemistry, 34 (5) : 823- 826.

Brand, W., Cuvelier, MC., Berset, C.,(1995). Use of the free radical method to assess antioxidant activity. Food Sci. Technol. 28, 25-30.

Demir, D.,(2013). Zeytinde Polifenol Oksidaz Enzimi, ZZ Review, Isparta, 29,68-73.

Fernandez-Orozco R, Roca M, Gandul-Rojas B, GallardoGuerrero L.,(2011). DPPH-scavenging capacity of chloroplastic pigments and phenolic compounds of olive fruits (cv. Arbequina) during ripening. J Food Compos Anal. 24,858-864.

Kadakal, E.,(2009). Gemlik Yöntemi İle İşlenmiş Gemlik Tipi Sofralık Zeytinleri Antioksidan Özellikleri Ve Fenolik Profilleri, Yüksek Lisans Tezi, İstanbul Teknik Üniversitesi, Fen Bilimleri Enstitüsü, İstanbul.

Karadeniz, F., Burdurlu, H., Koca, N., Soyer, Y.,(2005). Selected Grown Fruits and vegetables Antioxidant Activity in Turkey, Turkish Journal of Agriculture and Forestry, 29,297-303.

Kaya, Ü. ve Mutlu, T.K.,(2010). İznik’te Yetiştirilen Gemlik Zeytininin ve Yağının Bazı Fiziksel, Kimyasal ve Antioksidan Özelliklerinin Belirlenmesi. CU Institute of Science and Technology,22-1.

Keçeli, T. ve Büyükaslan, Y., (2008). Hatay'da Yetiştirilen Bazı Zeytinlerin Antioksidan Etkilerinin Belirlenmesi. Türkiye 10. Glda Kongresi. Turkey, May1s 21-23, Erzurum.

Pirgün, Y. ve Keçeli, T.,(2008). Hatay'da Yetiştirilen Gemlik ve Halhalı Zeytinlerinin Antioksidan Etkilerinin Belirlenmesi. CU Institute of Science, 18-1. 
R Re, N., Pellegrini, A., Proteggente, A., Pannala, M., Yang, C.,(1999). Antioxidant activity of applying a colorimetric assay of an improved ABTS radical cation. Free Radical Biology and Medicine, 26,12311237.

Tokuşoğlu, Ö.,(2008). Sofralık Zeytinlerde, Zeytiyağında, Zeytin Ürünlerinde Ve Zeytin Karasuyunda Antioksidan Etkili Polifenoller Ve Biyoaktif Bileşiklerin Eldesinde Nanoteknoloji Uygulamaları, $I$. Ulusal Zeytin Öğrenci Kongresi, Edremit-Balıkesir.

Uceda, M. ve Frías, L. (1975). Harvest dates: Evolution of the fruits oil content, oil composition and oil quality. Proceedings II. Seminario Oleícola Internacional (pp. 125-128). COI: Córdoba.

Yemişçioğlu, F., Gümüşkesen, A.S., Otağ, R.M.,(2001). Zeytinyağ1 üretiminde kullanılan sürekli sistemler ve bu sistemlerin klasik presleme yöntemi ile karşılaştırılması. TMMOB Glda Mühendisliği Dergisi, 9, $26-31$. 